\title{
Are People Ashamed of Paying with Food Stamps?
}

Robert Breunig

Department of Statistics and Econometrics, The Australian National University, Australia

and

Indraneel Dasgupta

School of Economics,

University of Nottingham, United Kingdom

\section{WORKING PAPERS IN ECONOMICS AND ECONOMETRICS}

No. 382

Faculty of Economics and Commerce

and

Economics Program, Research School of Social Sciences Australian National University

November 1999

National Library of Australia Card Number

and ISBN Number 0868323823 


\title{
Are People Ashamed of Paying with Food Stamps?•
}

\author{
Robert Breunig \\ Department of Statistics and Econometrics, \\ The Australian National University, Australia \\ and \\ Indraneel Dasgupta \\ School of Economics, \\ University of Nottingham, United Kingdom
}

\section{Address for Correspondence:}

Robert Breunig

Department of Statistics and Econometrics, Faculty of Economics and Commerce,

The Australian National University; Canberra ACT 0200, Australia.

Phone: 61(02)6249-4991 Fax: 61(02)6249-0087 E-mail: Robert.Breunig@anu.edu.au

November 30, 1999

JEL Classification No.: I38

Key Words: Food Stamp Program, Cash Transfers, Cash-out Puzzle, Marginal Welfare Stigma, Engel Curves.

- We thank Thomas Fraker of Mathematica Policy Research, Inc. for generously providing us the data used in this paper. We have benefited from helpful discussions with Deborah-Cobb Clark, Richard Disney, Craig Gundersen and from comments and questions by seminar participants at the Australian National University and Sydney University. We acknowledge financial support from the USDA. 


\title{
Are People Ashamed of Paying with Food Stamps?
}

\begin{abstract}
Levedahl (1995) claims that marginal 'welfare stigma' causes a dollar of food to provide less utility if bought with food stamps rather than cash, and that this explains why, in the United States, the marginal propensity to consume food out of food stamps is larger than that out of income. This hypothesis has been advanced to explain the so-called 'cash-out puzzle': the empirical observation that the marginal propensity to consume food out of food stamps is much higher than that out of income, even for households who spend some cash income on food. We question the claim that stigma explains the cash-out puzzle. We develop a theoretical model to show that marginal welfare stigma is not sufficient to generate the puzzle, and use it to identify the restrictions imposed by the hypothesis that the puzzle is indeed caused by such stigma. Estimates from Engel curves using parametric and nonparametric methods are shown to be inconsistent with the stigma hypothesis.
\end{abstract}




\section{Introduction}

This paper investigates the hypothesis that an additional dollar worth of food bought with food stamps provides less utility than one bought with cash due to welfare stigma. It has been claimed (Levedahl (1995)) that this hypothesis explains the so-called 'cash-out puzzle', i.e., the tendency of the marginal propensity to consume food out of food stamps to be much larger than that out of cash income, noted in studies of the Food Stamp Program (FSP) in the United States. We develop a theoretical model to examine the robustness of this claim and to identify the major restrictions imposed on consumption behavior of agents by this hypothesis. Using data from a cashout experiment that have been used to advance the stigma hypothesis, we investigate whether these empirical restrictions indeed hold. Our empirical results cast doubt on the (marginal) stigma hypothesis, and thus bring into question its usefulness as an explanation of the cash-out puzzle. They also bring into question the very relevance of the cash-out puzzle for policy debates regarding FSP.

A better understanding of welfare stigma and the role it plays in the cash-out puzzle is crucial for policy formulation. It is widely believed that social stigma associated with receiving welfare benefits imposes significant non-pecuniary costs on recipients. ${ }^{1}$ Since using food stamps necessarily involves revealing one's status as a welfare recipient, it seems eminently plausible that such nonpecuniary costs can be significantly reduced if food stamp benefits are paid in cash instead of in coupons. The United States Department of Agriculture has begun switching away from the traditional food coupons to schemes such as electronic benefit transfers (EBT) (see Beecroft, et al., 1994) and this has been partly justified by arguments about welfare stigma. Switching to EBT or cash transfers may also generate administrative savings and reduce monitoring costs. Conversely, if these changes induce more people to enter the program, costs may in fact rise.

If, as Levedahl (1995) argues, it is the case that welfare stigma generated by the very use of coupons has the consequence of increasing food consumption by welfare recipients, then a move to a cash transfer or EBT should reduce food purchases. Strong political support for the Food Stamp

\footnotetext{
1 The existence of a lump sum cost of participation due to such stigma has been advanced as an explanation of why many eligible households choose not to participate in welfare programs such as AFDC (renamed Temporary Assistance for Needy Families, TANF) and the Food Stamp program. A large literature exists on
} 
Program (FSP) is predicated largely on the belief that food stamps generate greater amounts of food expenditure than cash transfers. Improving the nutritional levels of the poor is widely perceived to be a major goal of public policy. The coupon-based system may then be justified in terms of its impact on food consumption. If, however, the use of coupons doesn't actually impose any significant stigma costs on recipients, and/or if the cash-out puzzle is generated by some other factor, then a (properly designed) move away from the present coupon-based system need not necessarily lead to a significant fall in food consumption. Clearly, a deeper understanding of the role stigma might play in generating the cash-out puzzle is crucial to an informed debate.

In providing grounds for questioning the usefulness of the marginal stigma hypothesis as an explanation for the cash-out puzzle, the present paper contributes to this debate. Our aim in this paper is limited to contesting the adequacy of the existing stigma based explanation. We thereby attempt to establish the case for seeking an alternative explanation. ${ }^{2}$

The plan of the paper is as follows. We begin by discussing some of the theoretical issues involved in the cash-out puzzle and the marginal stigma hypothesis. We also provide a review of the relevant literature in this section. We introduce our theoretical model in Section III and provide sufficient and necessary conditions for stigma to generate the cashout puzzle. In Section IV, we briefly discuss the data and the econometric models. We justify these models using non-parametric regression estimates. Section V contains the main results from the estimation and the evidence against marginal welfare stigma as an explanation of the cash-out puzzle. Our empirical results also bring into question the common belief that a move from the present FSP to a system based on cash welfare payments (or EBT) will necessarily lead to a significant fall in food consumption. In doing so, they cast doubt on the relevance of the cash-out puzzle for policy debates regarding changes in FSP. We conclude in Section VI.

this issue. See, for example, Moffitt (1981, 1983), Ranney and Kushman (1987), Besley and Coate (1992), Blank and Ruggles (1996) and Gundersen and Andrews (1999).

${ }^{2}$ We have advanced an alternative explanation elsewhere (Breunig and Dasgupta (1999)). 


\section{Theoretical Issues}

The basic theoretical model of the effects of government food subsidy on household expenditure, originally due to Southworth (1945), assumes that individuals take into account only their total income, not the form in which they receive it, in making their consumption decisions. In other words, they consider (a) a dollar of income received from own sources and that from welfare payments equivalent, and (b) a dollar of cash income received from the government and a dollar worth of food stamps equivalent. The model thus predicts the following demand behavior for unconstrained individuals, i.e., for individuals who spend more on food than they receive in food stamps. First, a 'cash-out', i.e., a reduction in food stamps associated with an identical increase in either the agent's own income or in his cash welfare benefits, will keep his food consumption invariant. Second, the marginal propensity to consume food out of own cash income, food stamps and cash welfare payments should all be identical. Under the basic model, a change in the form of benefit from stamps (which can only be used to purchase food) to cash should only induce a change in expenditure if an individual is 'constrained.' Constrained individuals would prefer to spend less on food than they receive in stamps, but the in-kind nature of the benefit prevents them from spending the income on non-food consumption.

The cash-out puzzle arises from the empirical observation that, contrary to the predictions of the traditional model, the marginal propensity to consume food out of money income seems to be significantly less than that out of food stamps, even for unconstrained households. Fraker (1990) reviews seventeen studies using different data-sets, where the marginal propensity to consume food out of money income is between .05 and .1 and that out of food stamp benefits three to ten times larger. While the traditional model can explain this feature of aggregate data only if the proportion of unconstrained households is large, most studies actually show this group to be on the order of ten to fifteen percent. In the experimental data from San Diego used below, this constrained group is only about five percent. Thus, this large estimated marginal propensity to consume food out of food stamps at the aggregate level, relative to money income, would seem to contradict conventional economic theory. 
While this discrepancy is of interest in its own right, studies have drawn an important policy implication from it as well. The Southworth model assumes (and most existing studies seem to take for granted) that agents do not distinguish between money income from own sources and welfare benefits paid in cash. If this is true, then the empirical puzzle would imply that a cash-out of the food stamps program, i.e. its replacement by a system of cash welfare benefits (or EBT), would also reduce food consumption significantly. Such a possible policy implication in turn provides an important motivation for developing a proper analysis and explanation of the cash-out puzzle.

Levedahl (1995) has suggested an interesting explanation for the puzzle. He considers a standard utility maximization model where the agent consumes two goods: food and a composite of all other goods. The model is extended by allowing food bought with food stamps and that bought with income to be less than perfect substitutes. Levedahl assumes a marginal 'stigma' associated with food stamps, which causes the marginal utility of food bought with food stamps to be less than that of food purchased with cash, and conjectures that such marginal stigma generates the cash-out puzzle in this model. He proceeds to conclude that "if the FSP is reformed in a way that reduces the stigma associated with food stamps (e.g. through the implementation of an Electronic Benefit System), it follows that food expenditure by recipients will fall” (p. 962).

Levedahl's argument however suffers from two major weaknesses. First, he does not provide a rigorous theoretical justification for the view that his extension of the standard model is either necessary or sufficient to generate demand behavior in accordance with the cash-out puzzle. If it is neither necessary nor sufficient, then, even if it is the case that food purchases made with food stamps do impose non-pecuniary costs, his policy conclusion does not necessarily hold. Second, he does not provide any independent empirical evidence to justify the assumption of marginal stigma. Even if marginal stigma is sufficient to explain the puzzle, in the absence of such evidence, it does not follow that it is indeed the correct explanation (unless it is also necessary). Hence, even if marginal stigma is a sufficient theoretical explanation, in the absence of any empirical backing for it, this explanation does not allow one to draw any policy conclusion from the observed differences in the marginal propensities to consume out of stamps and cash income. Therefore, both gaps in Levedahl's argument 
need to be addressed before one can seek to draw policy conclusions. In this paper we address these issues.

We start with Levedahl's model of consumer behavior in the presence of marginal stigma, where the agent consumes food and a composite non-food consumption good. Food may be purchased with cash as well as coupons, and, as in Levedahl's case, the marginal utility of food purchased with cash is greater than that purchased with coupons. We first show that marginal stigma, by itself, is neither necessary, nor sufficient to predict that an unconstrained agent will reduce his consumption of food when food stamps are converted to cash income. We proceed to investigate whether the marginal stigma hypothesis can be resurrected at a theoretical level by identifying additional conditions under which marginal stigma indeed turns out to be equivalent to consumption behavior in accordance with the cash-out puzzle. We show that this is the case if and only if the nonfood item is a normal good.

Our model generates three testable predictions. First, marginal propensity to consume food out of cash welfare payments should be the same as that out of non-welfare income. ${ }^{3}$ Levedahl (1995, p. 962, fn. 3) indeed seems to consider this an implication of his model, but refrains from testing it. Second, if it is indeed the case that the non-food item is a normal good, then the marginal propensity to consume food out of food stamps must be greater than that out of cash income for unconstrained agents. These two conditions can be combined to yield our third prediction. If the nonfood item is a normal good, then the marginal propensity to consume food out of food stamps must be greater than that out of cash welfare benefits. Violation of any of these conditions would bring into question the marginal stigma hypothesis.

We test these predictions with data generated by a cash-out experiment carried out in San Diego county, data that Levedahl also uses. Under assumptions typical of the food stamp literature, we find that the non-food composite good is indeed a normal good and that the marginal propensity to consume food out of food stamps is greater than that out income for unconstrained stamp households. Thus, the data satisfy the second restriction imposed by the marginal stigma model. 
However, for check-receiving households participating in the cash-out, the marginal propensity to consume out of checks is also much higher than that out of cash income, violating the first prediction of the model. Indeed, we fail to reject the hypothesis that the marginal propensity to consume food out of checks is different from that out of stamps, which violates the third prediction as well. Since reduction of welfare stigma through a cash-out does not appear to reduce food consumption, marginal welfare stigma seems misleading as an explanation for the difference in marginal propensities to consume food out of welfare and non-welfare income. Furthermore, the standard policy implication drawn from the cash-out puzzle itself also seems questionable.

Evaluating the marginal stigma hypothesis by means of estimates derived from all households is, however, somewhat misleading. Such a procedure actually implies testing the stigma hypothesis jointly with the auxiliary hypothesis that multi-person households behave as if they are individual decision-makers. In the food stamp literature this assumption is ubiquitous. However, as the recent literature on intra-household decision-making shows, it is actually quite questionable. ${ }^{4}$ Intrahousehold distribution of resources may depend on the composition of total household income. Conversion of in-kind welfare income to cash income may simultaneously lead to a change in the intra-household division of resources. This, in turn, may lead to a multi-person household exhibiting consumption behavior that cannot be explained in terms of the household maximizing as an individual. ${ }^{5}$ Thus, one may interpret the estimates derived from all unconstrained households as implying a rejection of the unitary model of household decision-making, rather than that of the stigma hypothesis itself.

In order to conduct a more 'pure' test of the stigma hypothesis, we separately consider the group of single-adult headed unconstrained households as well. We find that individuals who received welfare checks instead of the traditional coupons had a larger marginal propensity to consume food out of such cash welfare payments than out of non-welfare income. Furthermore, we

\footnotetext{
${ }^{3}$ Marginal stigma is presumably due to the fact that one reveals one's status as a welfare recipient to others by paying with coupons, and such revelation causes disutility ('shame'). One doesn't need to reveal one's status in this sense if one is paying with cash, regardless of the source of such cash.

${ }^{4}$ See, for example, Alderman et al. (1995) and Haddad et al. (1997).
} 
find no evidence of any difference between the marginal propensities to consume food out of cash income and food stamps for stamp-receiving unconstrained individuals, even though the marginal propensity to consume food is less than one. Nor do we find any evidence that the marginal propensity to consume food out of stamps is larger than that out of checks. Thus, our results show no evidence of individual agents' consumption behavior satisfying even one of the restrictions generated by the marginal stigma hypothesis. Our results therefore cast doubt on the assumption of marginal stigma itself, and question its appropriateness as an explanation of the cash-out puzzle. The results also provide further grounds to question the standard belief that a cash-out of the food stamps program will lead to a reduction in food consumption.

\section{The Model}

Consider an individual who consumes two goods, food and a composite non-food item. Food is however available from two different sources: cash purchases and purchases through food stamps. Purely for notational simplicity, we shall assume that all prices are equal to one. Let the agent's preferences be given by the utility function:

$$
u=u(x, f, s),
$$

where $x$ is the amount of the non-food good, $f$ is the amount of food purchased with cash and $s$ is the amount of food purchased with coupons. The utility function is assumed to be increasing and differentiable up to the second degree in its arguments and strictly quasi-concave in (x, f). The agent has a cash income I, which consists of his non-welfare income, and cash welfare payments (if any).

In the standard framework, agents consider food purchased with cash income and that purchased with coupons identical, so that the marginal rate of substitution between these two items is unity. Levedahl (1995, p. 962) introduces marginal stigma into his model through the assumption that 'the marginal utility of food bought with food stamps is less than the marginal utility of food bought with income'. Thus, formally, marginal welfare stigma is captured by the following assumption.

\footnotetext{
${ }^{5}$ Elsewhere (Breunig and Dasgupta (1999)) we develop and test a model where the cash-out puzzle is in fact generated by changes in intra-household distribution of resources occurring as a result of changes in the composition of total household income.
} 
A1. $u_{s} / u_{f}<1$

We shall first show that, by itself, marginal welfare stigma is not sufficient to generate the cash-out puzzle; indeed, nor is it necessary. To do this, it is necessary to first interpret the cash-out puzzle slightly formally.

First note that the agent's optimization problem can be written as:

$\operatorname{Max} u(x, F-s, s)$

subject to:

$$
x+F=Y,
$$

and

$$
F \geq s
$$

where $\mathrm{F}$ is the total amount of food purchased with cash and coupons, $F=s+f$, and $\mathrm{Y}$ is the total income of the agent from all sources, cash and coupons, $Y=s+I$.

Constraint (2) above holds with strict inequality if an agent is unconstrained. Then, the solution to the agent's optimization problem subject to the budget constraint (1) yields, in the standard way, the demand functions: $x=x(Y, s)$ and $F=F(Y, s)$. We shall assume that both demand functions are differentiable in their arguments. Note that the cash-out puzzle only refers to the behavior of unconstrained individuals. There is no cash-out puzzle for constrained individuals: expenditure is expected to change under a cash-out for these individuals. Hence, throughout the rest of this section, we shall assume that the agent is unconstrained. Note further that the marginal propensity to consume food out of non-welfare income is the same as that out of cash welfare income, both being given by $F_{Y}$. Clearly, this is true for the non-food item as well. Given cash income, a change in the amount of stamps changes total food consumption both directly, and indirectly, through its impact on total income from all sources, Y. The marginal propensity to consume food out of an additional dollar worth of stamps is thus given by $\left[F_{Y}+F_{s}\right]$. 
An agent's behavior exhibits the cash-out puzzle if the marginal propensity to consume food out of cash income is less than that out of stamps, i.e., if $F_{Y}<F_{Y}+F_{s}$. In that case, since $F_{s}>0$, a cash-out, i.e., a conversion of part or whole of the coupon component in his income to cash income which leaves his total income from all sources, Y, constant, also leads to a fall in his total purchase of food. The cash-out puzzle may therefore be interpreted equivalently as the following restriction on the agent's demand behavior.

$\mathrm{C} 1: \mathrm{F}(\mathrm{Y}, \mathrm{s})$ is increasing in $s$.

We are now ready to establish that marginal welfare stigma in Levedahl's sense is neither necessary nor sufficient to explain the cash-out puzzle.

Proposition 1. Al neither implies, nor is implied by, $C 1$.

The proof consists of two counterexamples. First suppose that the agent's preferences are given by the utility function:

$$
u=\frac{s}{2}+f+2 \ln (x+1)
$$

Obviously, the agent's preferences satisfy A1. Yet, as can be easily checked, the agent's demand for the non-food item remains invariant when the coupon component is replaced partly or wholly by an equivalent cash payment. Thus the agent's consumption behavior will be exactly as predicted by the traditional Southworth (1954) model, even though the utility function satisfies the marginal stigma condition. Hence, marginal welfare stigma, by itself, does not necessarily lead to the cash-out puzzle. Now suppose instead that the agent's preferences are given by the utility function:

$$
u=k s+f+2(x+s)^{1 / 2},
$$

where $k \geq 1$. Then, clearly, $u_{s} / u_{f}>1$. Hence, A1 is violated; in fact, foods purchased with coupons provide a higher marginal utility than food purchased with cash. ${ }^{6}$ Yet, since the agent's consumption of the non-food item increases as the coupon component in his income is replaced by cash, $\mathrm{C} 1$ must be satisfied. This shows that marginal welfare stigma is not necessary to generate the cash-out puzzle.

\footnotetext{
${ }^{6}$ See Fraker (1990, pp. A24-A26) for some plausible examples where this may occur.
} 
Thus, marginal welfare stigma in Levedahl's sense, by itself, is neither sufficient nor necessary to predict demand behavior in accordance with the cash-out puzzle. Hence, empirical tests of the cash-out puzzle, by themselves, do not allow one to draw any inference whatsoever about the presence or otherwise of marginal welfare stigma.

A natural question to ask therefore is whether it is possible to identify conditions under which marginal stigma does in fact turn out to be equivalent to demand behavior in accordance with the cash-out puzzle. Furthermore, since our interest in such a restriction derives from its possible use in developing an empirical test of the marginal stigma hypothesis itself, this condition should take the form of some empirically verifiable property of demand functions. We now establish that this restriction is indeed nothing but the requirement that the non-food item be a (strict) normal good. Note that in both our counter-examples presented above, for unconstrained agents, the income elasticity of demand for the composite non-food item is zero.

\section{Proposition 2.}

(a) Al implies $C 1$ if and only if $x$ is increasing in $Y$.

(b) Cl implies Al if and only if $x$ is increasing in $Y$.

Proof: See the appendix.

The intuition behind these results is simple. The presence of marginal stigma implies that purchase of food through coupons is an inefficient way of acquiring food. Conversion of coupons to cash is therefore intuitively similar to an increase in the agent's income in terms of its effect on consumption. $^{7}$

Thus, if marginal stigma does in fact exist, we should expect consumption behavior of unconstrained individuals to satisfy the following restrictions. First, the marginal propensity to consume food out of cash non-welfare income should be the same as that out of cash welfare payments. Second, and more importantly, if the marginal propensity to consume food out of cash income is less than one, then consumption behavior should exhibit the cash-out puzzle in its standard

\footnotetext{
${ }^{7}$ It is easy to see that, if an agent is constrained, then, given marginal stigma, normality of the composite nonfood good is sufficient, but not necessary, to generate the cash-out puzzle, i.e., C1. On the other hand, for such an agent, if the non-food good is inferior, then marginal stigma does not necessarily imply $\mathrm{C} 1$. In the
} 
form: the marginal propensity to consume food out of food stamps should be greater than that out of non-welfare income. From a policy perspective, the third restriction is the most important. This is the following: if the marginal propensity to consume food out of cash income is less than one, then the marginal propensity to consume food out of food stamps should be greater than that out of cash welfare benefits. This restriction implies that a cash-out of FSP, i.e. the substitution of food coupons by cash welfare payments, will necessarily lead to a fall in food consumption when the composite non-food item is a normal good. This is the policy implication routinely drawn from the empirical puzzle in its standard form. Violation of any of the three conditions specified above would cast doubt on the marginal stigma hypothesis itself. We shall test these restrictions with data from the San Diego cash-out experiment.

\section{Data and Econometric Issues}

The empirical literature on the effects of FSP has been limited by the lack of experimental data, which makes it difficult to directly assess the impact, on food expenditure, of additional cash welfare payments made available by a cash-out of FSP. This perhaps partly explains the assumption common in this literature that such a cash-out of FSP will have the same effect as an equivalent increase in non-welfare income.

To address this problem, the Food and Consumer Service of the US Department of Agriculture undertook a number of experiments in the late 1980s where food stamp participants were sent checks instead of food stamp coupons. Four experiments were conducted, one in San Diego county, two in Alabama, and one in the state of Washington. ${ }^{8}$ The data set we use is from the cashout experiment in San Diego county since there is universal agreement that the cash-out puzzle is present in this data and this experiment has been used by Levedahl (1995) to advance the stigma hypothesis. For the cash-out experiment, 600 families were selected at random from the food stampreceiving population and their benefits were converted from coupons to checks. An additional 600

Southworth model, however, C1 must necessarily hold for a constrained agent, regardless of the nature of the non-food item.

${ }^{8}$ These are reviewed by Fraker, Martini, and Ohls (1995), who also provide more detailed references to the individual studies. 
families, who continued to receive benefits in the form of coupons, were selected as a control group. The families were interviewed several months after the cash-out was implemented. ${ }^{9}$

In order to investigate the consumption behavior of households in our data set, we estimate the Engel curve for food expenditure for check and stamp receiving households. Many different functional forms have been used to estimate Engel curves for food expenditure. Here, we consider the following models.

$$
f \exp _{i}=\alpha+\beta y_{i}+\gamma f s b_{i}+X_{i}^{\prime} \delta
$$

$$
\ln \left(f \exp _{i}\right)=\alpha+\beta \ln \left(y_{i}+f_{s} b_{i}\right)+\gamma\left(\frac{f_{s} b_{i}}{\left(y_{i}+f s b_{i}\right)}\right)+X_{i}^{\prime} \delta
$$

where fexp is food expenditure, $y$ is cash income, $f s b$ is stamp (or check) benefits, and $X$ is a vector of household characteristics.

The linear model (a) is consistent with utility maximization. However, it embodies the unrealistic restriction that the share of food in overall expenditure remain constant at all levels of income. The double-log model (b) is not consistent with utility maximization, but has generally been found to provide a better fit to the data. It is also quite flexible, placing few restrictions on the share of food in total expenditure and the rate of change of the marginal propensities to consume out of cash income and benefits.

As a check on the specification of the model, we begin by considering nonparametric regressions of food expenditure on total income and the log of food expenditure on log of total income. Figure 1 shows the fitted values from these regressions for the unconstrained stamp households and all of the check households. Figure 2 shows the fitted values from the non-parametric regressions using only the single-adult headed households ${ }^{10}$.

\footnotetext{
${ }^{9}$ Detailed information on the design and data collection of the San Diego cash-out experiment may be found in Ohls, Fraker, Martini, and Ponza (1992).

${ }^{10}$ The bandwidth is chosen by leave-one-out cross-validation, resulting in some under-smoothing of the regression lines, which is typical. We prefer this method, however, since it is easier for the observer to provide additional smoothing with the eye than to 'unsmooth' an overly smoothed regression function.
} 
Figure 1 would seem to support the double-log specification over the linear one, as there is less non-linearity present in this specification. For the single-adult headed households, there appear to be fairly significant non-linearities in both specifications. We undertake sensitivity testing for these non-linearities. This is discussed below.

In the double-log specification, there appears to be a larger marginal propensity to consume food out of total income for stamp recipients than for check recipients. This seems less evident in the linear specification. We note however that the two income sources are lumped together for these regressions and that we do not control for household characteristics. In what follows, we present the parametric results from both specifications. The substantive results are the same under either model.

We estimate the Engel curve for food expenditure with two purposes in mind. First, we wish to determine whether the cash-out puzzle is present in our data. If it is, we then wish to check whether the restrictions from Section III hold, i.e. whether the data are consistent with the stigma hypothesis.

The point of our econometric estimation is to map out the expansion path of food expenditure. The Engel curve is thought of as arising from utility maximizing behavior of agents. At different income and benefit levels, we estimate the optimal choice of food expenditure. The problem which arises is that individuals who receive food benefits in the form of food stamps are facing a kinked budget constraint. Stamp-receiving individuals who are observed to be on the kink (food expenditure equal to food stamp benefits) or on the flat portion of the budget constraint (food expenditure less than food stamp benefits) are not at an 'optimal' point for their income level. Presumably these 'constrained' individuals would change their behavior if the food stamp benefit were changed to cash/check. The Engel curve we wish to estimate is one which traces out a behavioral relationship. The behavioral relationship for 'constrained' and 'unconstrained' individuals is clearly different. Furthermore, the cash-out puzzle only refers to the behavior of unconstrained individuals. There is no cash-out puzzle for constrained individuals: expenditure is expected to change under a cash-out for these individuals. Therefore the comparison we wish to make using our estimated Engel curve is that between all check households and 'unconstrained' stamp households. We do this in two ways: 
separate estimation of these subgroups and pooled estimation using an intercept dummy variable for stamp households and interacting that dummy with each exogenous variable.

We estimate both models using a full range of explanatory variables to correct for receipt of other food subsidies, household composition, and household characteristics. The variables considered and used in the regressions are listed in the Appendix (Table A.1). We scale the food expenditure and income quantities by household size. We then include variables to control for the percentage of household members in different age groups, which presumably have different nutritional needs.

To determine which variables to include in the regression and to test the sensitivity of our models, we estimated both models for (1) the full data set; (2) the full data set using interactive dummies for the stamp recipients; (3) the check households only; and (4) the unconstrained stamp households only. We also conducted these four regressions using only single-adult headed households. Any variable which was significant in one of these regressions was included in all the regressions for the sake of completeness and comparison. The point was not to necessarily come up with the 'best' model, but to show that the results are robust to specification and variable inclusion. Furthermore, we considered it important to include variables for which strong a priori reasons exist for that variable to influence the dependent variable. We have resisted the temptation to further pare down the model or to drop variables with unexpected signs.

Further sensitivity analysis was conducted regarding our definition of single-adult headed household, the definition of income and the definition of household size (the number of people in the household and the number of people eating out of the same food supply were both considered as candidates). 101 observations had household and food consumption unit size data which conflicted with the information from the roster of individuals in the household. We constructed a corrected household size variable for these households and estimated the model with and without them. Some of the household characteristic variables and in one case, the sign of a coefficient, were affected by these changes. However, the main conclusions presented below regarding the marginal propensities to consume out of stamps, out of cash income, and out of checks remained essentially unchanged. The results presented below in Table 1 and Table 2 are robust to these considerations. 
We also explored the possibility of measurement error in the reported food expenditure data. It could be that there are many households considered 'unconstrained' who are in fact constrained and clustered very close to the 'kink' in the budget constraint. We allowed for food expenditure to be over-stated by five percent and ten percent and reestimated the model using that data to form the constraint. There was only one household within five percent of being constrained and less than twenty within ten percent. We estimated the model after re-classifying these twenty households, but there was no impact on the results.

In the single-adult household sub-samples, we tested various subgroups of the data to see whether the non-linearities visible in the non-parametric regressions presented any problem in estimation. For the single-adult headed check-receiving households, there were twelve observations with extremely low food expenditure which had a very large influence on the regression results. We included a dummy intercept term and a dummy interactive term with the income and food benefit variables to account for these households. (Dropping these observations altogether has a similar result on the outcome.) A similar search for problematic observations (particularly in the tails of the sample income distribution) and leverage points was done for the stamp-receiving households. We did not find such problems.

\section{Results}

Table 1 shows the estimated marginal propensities to consume out of food benefits and nonwelfare cash income for the check-receiving and unconstrained stamp-receiving households. ${ }^{11}$ Using interactive dummies on food benefit, (non-welfare) cash income, and household size, we fail to reject the hypothesis that the marginal relationship between food benefits, income and food expenditure is the same for the stamp and check households. The intercept dummy term is significant and positive, consistent with the observation that the stamp group has higher mean expenditure on food. We thus report the estimates from the pooled model, with only the intercept dummy included.

\footnotetext{
${ }^{11}$ Full regression results from pooled and separated regressions are provided in the Appendix in Tables A.2 and A.3. We include some discussion of the estimates of the control variables in the appendix as well.
} 
We observe strong evidence of the cash-out puzzle, in that the marginal propensity to consume food out of stamps is significantly larger than that out of (non-welfare) cash income. Our results are in strong agreement with others' that the cash-out puzzle is indeed present in this data. ${ }^{12}$ We also notice that the choice of functional form does not have much impact on the quantitative estimates of the marginal propensities to consume.

In Proposition 2 above, we established that, if the non-food item is a normal good, then, if it is the case that the marginal propensity to consume food out of stamps is greater than that out nonwelfare cash income, then the agent's preferences must satisfy marginal welfare stigma. We find that the non-food composite good is normal. Thus, the empirical result mentioned above, viz. that the marginal propensity to consume food out of stamps is significantly larger than that out of non-welfare income, seems to support the marginal stigma hypothesis. However, the other two implications of the marginal stigma hypothesis are violated by the data. The marginal propensity to consume food out of cash welfare benefits is considerably higher than that out of non-welfare income. Perhaps even more important is the fact that there is no significant difference between the marginal propensities to consume out of food stamps and cash welfare benefits. (This test is discussed in the Appendix, Table A.3.) Thus, the empirical evidence for the marginal stigma hypothesis, derived from considering all households in the sample, seems mixed.

The question therefore naturally arises as to whether one can draw more unambiguous conclusions from the data. Note that we established our necessity result in Section III only for an individual decision-maker. For the model developed in Section III to be applicable to multi-adult households, one has to make the additional assumption that such households behave essentially like a single individual. As discussed in Section II, this assumption is questionable and will affect the econometric results, since we are pooling households which may be fundamentally different. Once one moves out of the unitary model of household decision-making, it is no longer true that marginal

\footnotetext{
${ }^{12}$ A simpler way of demonstrating the presence of the cash-out puzzle is to compare the means of the two groups, treating the stamp-receiving units as a control group. This is the approach of Fraker, Martini, and Ohls (1995) and they reach the same conclusion that we do. Levedahl (1995) estimates the double-log model using a slightly different set of explanatory variables, but reports almost identical marginal propensities to consume. $\mathrm{He}$ does not estimate the model for check-receiving households.
} 
welfare stigma is necessary for a multi-adult household's consumption behavior to exhibit the cashout puzzle, even if the composite non-food item is a normal good..$^{13}$

Therefore, estimates for single-adult headed households alone would seem to provide a more pure test of the marginal stigma hypothesis. We provide such estimates in Table 2 for the stampreceiving and check-receiving single-adult headed households. We provide results for the separate sub-samples, since we reject the hypothesis that the relationship between benefits, income and food expenditure is the same for these two groups.

For the stamp-receiving households, we find very small marginal propensities to consume out of both cash income and food stamp benefits and no significant difference between the two. Clearly, non-food items taken together constitute a normal good. Yet, neither the linear nor the double-log specification provides any evidence of a significant difference between marginal propensities to consume food out of cash income and food stamps. Thus, contrary to the prediction of the marginal stigma model, a cash-out puzzle does not seem to exist for single-adult headed households. Regardless of the specification used, the regression results contradict the model.

Now consider the other two predictions of the marginal stigma model identified in Section III. The first was that checks should be treated like income if it is indeed stigma that drives the cash-out puzzle. Our results contradict this prediction. We saw that the marginal propensity to consume food out of check benefits is significantly higher than that out of non-welfare income for all households (Table 1). The results from considering only check-receiving households (Table A.2 in the appendix) also provide strong evidence for this. It is true for single-adult headed check households as well. Regardless of which group we look at, checks are not being treated identically to cash income.

Lastly, consider the prediction that is most important for policy purposes. We find that the non-food item is indeed a normal good. The primary restriction generated by the marginal stigma hypothesis then was that the marginal propensity to consume food out of stamps should be significantly higher than that out of checks. Yet we do not find any significant difference in the marginal propensities to consume food from welfare benefits across the stamp and check groups when we look at all households (Table 1). If we confine our attention to single-adult headed households in

\footnotetext{
${ }^{13}$ See Breunig and Dasgupta (1999).
} 
either group, then the marginal propensity to consume food out of check benefits actually appears to be somewhat larger than that out of stamps (Table 2). The implication is that food consumption will not fall when benefits are converted from stamp to check, contrary to the most important prediction of the marginal stigma model.

In sum, all three restrictions on individual agents' demand behavior imposed by the marginal stigma hypothesis seem to be violated by our data. These results therefore put a question mark on the validity of the stigma-based explanation itself. There does seem to be a cash-out puzzle in the data, in that the marginal propensity to consume food out of stamps is significantly higher than that out of non-welfare income. However, this seems to be generated primarily by the consumption behavior of multi-adult households, and does not appear to be due to marginal welfare stigma. Furthermore, since these results indicate that food consumption will not fall when benefits are converted to cash, the cash-out puzzle in the data does not appear to have any direct relevance for the policy debate regarding changes in FSP. Our empirical results thus also seem to question the policy inference usually drawn from the observed difference in marginal propensities to consume out of food stamps and non-welfare income.

\section{Conclusion}

As is amply documented, there appears to be a large discrepancy between the marginal propensity to purchase food out of cash income and that out of food stamps. In this paper, we have examined both the formal and the empirical bases of the claim that marginal welfare stigma explains this puzzling empirical regularity. We have developed a model to show that this claim is formally correct for an individual decision-maker if and only if all non-food items taken together constitute a normal good. We have tested the major predictions of this model with data from the San Diego cashout experiment. The results presented here cast serious doubt on the appropriateness of stigma as an explanation for this empirical regularity. Our analysis points to the need for considering other factors, such as the dynamics of intra-household decision-making, as possible explanations for the cash-out puzzle. 
Furthermore, we do not find any empirical support for the common belief that conversion of food stamps to cash welfare benefits (or EBT) will lead to a significant fall in food consumption. Thus, our empirical results also bring into question the policy implication that is commonly drawn from the observed discrepancy between the marginal propensity to consume food out of cash income and that out of food stamps. In doing so, they cast doubt on the very relevance of the cash-out puzzle for debates regarding the consequences of a move from the present coupon based program to one based on some form of cash transfer.

In this paper we have only considered the effect of stigma on total food expenditure. There may be other marginal stigma effects which do not cause any changes in such expenditure. There is some evidence (Beecroft, et al., 1994) that benefit recipients make more trips to the store when they receive checks or electronic debit cards instead of food stamps. This may, perhaps, be interpreted as evidence of stigma. More frequent trips to the store may mean that recipients are buying more perishable food such as fruits and vegetables which may provide better nutritive value. It is not clear, however, what effect this should be expected to have on food expenditure. One interesting extension of this paper would be to consider differences in nutrition elasticities for cash and benefit income. 


\section{$\underline{\text { References }}$}

Alderman, H., P. Chiappori, L. Haddad, J. Hoddinott and R. Kanbur (1995): "Unitary Versus Collective Models of the Household: Is it Time to Shift the Burden of Proof?" The World Bank Research Observer, 10 (1, November): 1-19.

Beecroft, E., M. Ciurea, S. Hebert, R., N. Kutty, V. Leiter, and J. Maskeret (1994): The Evaluation of the Expanded EBT Demonstration in Maryland, Volume 3: System Impacts on Demonstration Stakeholders. USDA, Food and Nutrition Service, Office of Analysis and Evaluation.

Besley, T. and S. Coate (1992): "Understanding Welfare Stigma: Taxpayer Resentment and Statistical Discrimination", Journal of Public Economics (48): 165-183.

Blank, R. and P. Ruggles (1996): "When do Women Use Aid to Families with Dependent Children and Food Stamps? The Dynamics of Eligibility versus Participation", The Journal of Human Resources (31): 57-89.

Breunig, R. and I. Dasgupta (1999): "What's so Puzzling about the Cash-out Puzzle?" mimeo, Department of Statistics and Econometrics, The Australian National University.

Fraker, T. (1990): The Effects of Food Stamps on Food Consumption: A Review of the Literature, Washington, DC: USDA, Food and Nutrition Service.

Fraker, T., A. Martini, and J. Ohls (1995): "The Effect of Food Stamp Cashout on Food Expenditures: An Assessment of the Findings from Four Demonstrations", Journal of Human Resources, 30:4, 633-649.

Gundersen, C. and M. Andrews (1999): "A Reconsideration of Stigma in the Food Stamp Program", mimeo, USDA, ERS.

Haddad, L., J. Hoddinott and H. Alderman (eds) (1997): Intrahousehold Resource Allocation in Developing Countries. Baltimore: The Johns Hopkins University Press.

Levedahl, J. (1995): "A Theoretical and Empirical Evaluation of the Functional Forms Used to Estimate the Food Expenditure Equation of Food Stamp Recipients", American Journal of Agriculture Economics, 77 (November): 960-968.

Moffitt, R. (1983): “An Economic Model of Welfare Stigma", American Economic Review, 73 (December): 1023-1035.

Moffitt, R. (1981): "Participation in the AFDC Program and the Stigma of Welfare Receipt: Estimation of a Choice-Theoretic Model", Southern Economic Journal, (January): 753-62.

Ohls, J., T. Fraker, A. Martini, and M. Ponza (1992) The Effects of Cash-Out on Food Use by Food Stamp Program Participants in San Diego. Princeton, NJ: Mathematica Policy Research, Inc.

Ranney, C. and J. Kushman (1987): "Cash Equivalence, Welfare Stigma, and Food Stamps", Southern Economic Journal, 53 (April): 1011-27.

Southworth, H. (1945): "The Economics of Public Measures to Subsidize Food", Journal of Farm Economics, 68 (1): 37-43. 
Table 1

Unconstrained stamp households and all check households

\section{Linear Model}

$\begin{array}{cc}\text { MPC(FSB) } & 0.318^{* *} \\ & (0.089) \\ \text { MPC(Y) } & 0.046^{* *} \\ & (0.01) \\ \text { MPC(FSB) - } & 0.272^{* *} \\ \text { MPC(Y) } & (0.089)\end{array}$

Double-log Model

\begin{tabular}{cc}
\hline MPC(FSB) & $0.307 * *$ \\
& $(0.057)$ \\
MPC(Y) & $0.069 * *$ \\
& $(0.01)$ \\
MPC(FSB) - & $0.238 * *$ \\
MPC(Y) & $(0.053)$
\end{tabular}

MPC(FSB): Marginal propensity to consume out of food stamp benefits (check or coupon) MPC(Y): Marginal propensity to consume out of cash income

Numbers in parentheses are standard errors. Full regression results in Appendix Tables A.2 and A.3.

*significant at $90 \%$ level

**significant at $95 \%$ level

Table 2

Single-adult households

\begin{tabular}{ccc}
\hline Linear Model & Stamp & Check \\
\hline MPC(FSB) & 0.034 & $0.406^{*}$ \\
& $(0.181)$ & $(.167)$ \\
MPC(Y) & 0.018 & 0.016 \\
& $(0.021)$ & $(0.02)$ \\
MPC(FSB) - & 0.017 & $0.39^{*}$ \\
MPC(Y) & $(0.180)$ & $(0.167)$
\end{tabular}

\section{Double-log Model}

$\begin{array}{ccc}\text { MPC(FSB) } & 0.078 & 0.269 * * \\ & (0.114) & (0.111) \\ \text { MPC(Y) } & 0.009 & 0.032 \\ & (0.02) & (0.022) \\ \text { MPC(FSB) - } & 0.069 & 0.237 * * \\ \text { MPC(Y) } & (0.107) & (0.099)\end{array}$




\section{APPENDIX}

\section{Proof of Proposition 2:}

Given any consumption bundle $(\mathrm{x}, \mathrm{f}, \mathrm{s})$, let $\mathrm{t}$ be given as the solution to:

$$
u(x, f+t, 0)=u(x, f, s) .
$$

Then, from (3), we get:

$$
t=t(x, f, s) \text {. }
$$

Since the marginal utility of food, whether bought with coupon or cash, is positive,

$$
t_{s}>0,1+t_{f}>0 \text {. }
$$

Equations (3) and (4) imply that the agent's preferences can be represented by:

$$
u=u(x, f+t(x, f, s), 0)=V(x, f+t(x, f, s)) .
$$

It follows from (5) that the marginal rate of substitution between food bought with stamps and that bought with cash is given by:

$$
\frac{V_{s}}{V_{f}}=\frac{t_{s}}{1+t_{f}} .
$$

From (6) we get:

A1 is equivalent to $\left[t_{s}-t_{f}-1<0\right]$.

Now note that, from (5), the agent's maximization problem can be written as:

$$
\underset{x, F}{\operatorname{Max}} V(x, F+t(x, F-s, s)-s),
$$

subject to (1) and (2).

Under a cash-out, the agent's overall budget constraint, (1), remains unchanged, while (2) is nonbinding, since the agent is unconstrained by assumption. Let the marginal rate of substitution between the non-food item and total food purchased be given by:

$$
V_{x} / V_{F}=g(x, F+t(x, F-s, s)-s)=G(x, F, s) .
$$

Since the agent's total income from all sources, Y, remains constant under a cash-out, C1 is equivalent to the requirement that the agent's consumption of the non-food item increase under a cash-out. It is obvious from P2 that the agent's consumption of the non-food item will increase under a cash-out if and only if the marginal rate of substitution between the non-food item and total food purchased increases as the coupon component of his income is reduced. More formally, we have:

$\mathrm{C} 1$ is satisfied if and only if $G_{s}<0$. 
Now, since, using (8) we have:

$$
G_{s}=\frac{\partial g}{\partial(F+t(x, F-s)-s)}\left[t_{s}-t_{f}-1\right]
$$

using (7) and (9) we get:

$$
\text { A1 implies } \mathrm{C} 1 \text { if and only if }\left[\frac{\partial g}{\partial(F+t(x, F-s)-s)}>0\right] \text {, }
$$

and

$$
\text { C1 implies A1 if and only if }\left[\frac{\partial g}{\partial(F+t(x, F-s)-s)}>0\right] \text {. }
$$

Now note that (8) implies $\left[\frac{\partial g}{\partial(F+t(x, F-s)-s)}\left(1+t_{f}\right)=G_{F}\right]$. Since $1+t_{f}>0$, we have:

$$
\left[\frac{\partial g}{\partial(F+t(x, F-s)-s)}>0\right] \text { if and only if }\left[G_{F}>0\right] \text {. }
$$

It is easy to see that $\left[G_{F}>0\right]$ if and only if the demand function for the composite non-food item, $x(Y, s)$, is increasing in Y. Proposition 2 follows immediately from (10), (11) and (12). 
Table A.1

Variable definitions

\begin{tabular}{|l|l|}
\hline Variable & Definition \\
\hline FEXP & $\begin{array}{l}\text { Expenditure on food prepared and eaten at home per household } \\
\text { member }\end{array}$ \\
\hline LNFEXP & Natural log of food expenditure per household member \\
\hline INC & Cash income per household member \\
\hline FSB & Food stamp benefit (check or stamp) per household member \\
\hline LNTOTINC & Natural log of cash and benefit income per household member \\
\hline PROP & $\begin{array}{l}\text { Proportion of food stamp benefits in total cash and benefit } \\
\text { income }\end{array}$ \\
\hline HHSIZE & Household size \\
\hline LNHHSIZE & Natural log of household size \\
\hline GIFT & Gift food received per household member \\
\hline WIC & In-kind food commodity donations per household member \\
\hline ASIAN & $=1$ if household head is Asian \\
\hline BREAK & Breakfast subsidy per child \\
\hline LUNCH & Lunch subsidy per child \\
\hline ASGUEST & Weekly meals eaten as guest per household member \\
\hline BYGUEST & $\begin{array}{l}\text { Weekly meals eaten by guests in the household per household } \\
\text { member }\end{array}$ \\
\hline FEM & $=1$ if female head \\
\hline HH0_1 & Fraction of household between 0 and 1 year old \\
\hline HH2_17 & Fraction of household between 2 and 17 years old \\
\hline HH61p & Fraction of household over 60 years old \\
\hline STAMP & $=1$ if household received food stamps \\
\hline LFE & $=1$ if household has extremely low food expenditure \\
\hline
\end{tabular}

Other variables which proved to be insignificant for every sub-sample analyzed and for all models included wage, education, home ownership and race dummies other than Asian, and quantity of home produced food. None of these were included in the regression results shown below. 
Table A.2

Regression Results for Linear Model (a)

\begin{tabular}{|c|c|c|c|c|c|}
\hline & & & & Single-Adult hea & ouseholds only \\
\hline & $\begin{array}{l}\text { Pooled } \\
\text { Sample } \\
(n=953)\end{array}$ & $\begin{array}{c}\text { Unconstrained } \\
\text { Stamp } \\
(n=487)\end{array}$ & $\begin{array}{c}\text { Check } \\
(n=466)\end{array}$ & $\begin{array}{c}\text { Unconstrained } \\
\text { Stamp } \\
(\mathbf{n}=\mathbf{2 8 1})\end{array}$ & $\begin{array}{c}\text { Check } \\
(\mathrm{n}=\mathbf{2 8 3})\end{array}$ \\
\hline FSB & $\begin{array}{l}.318 * * \\
(.089)\end{array}$ & $\begin{array}{l}.416^{* *} \\
(.132) \\
\end{array}$ & $\begin{array}{l}.221 * \\
(.122)\end{array}$ & $\begin{array}{c}.034 \\
(.181)\end{array}$ & $\begin{array}{c}0.406 * \\
(.167)\end{array}$ \\
\hline INC & $\begin{array}{c}.046 * * \\
(.01)\end{array}$ & $\begin{array}{l}.051 * * \\
(.014)\end{array}$ & $\begin{array}{l}.037 * * \\
(.014)\end{array}$ & $\begin{array}{c}.018 \\
(.021)\end{array}$ & $\begin{array}{l}.016 \\
(.02)\end{array}$ \\
\hline HHSIZE & $\begin{array}{c}-1.362 * * \\
(.258)\end{array}$ & $\begin{array}{c}-1.183^{* * *} \\
(.362)\end{array}$ & $\begin{array}{c}-1.488 * * \\
(.371)\end{array}$ & $\begin{array}{c}-1.062 \\
(.70) \\
\end{array}$ & $\begin{array}{c}-1.853 * * \\
(.724)\end{array}$ \\
\hline GIFT & $\begin{array}{c}.217 \\
(.136) \\
\end{array}$ & $\begin{array}{l}.704 * * \\
(.231)\end{array}$ & $\begin{array}{l}-.015 \\
(.173) \\
\end{array}$ & $\begin{array}{l}.732 * * \\
(.276)\end{array}$ & $\begin{array}{c}.081 \\
(.204) \\
\end{array}$ \\
\hline WIC & $\begin{array}{c}-.27 \\
(.187)\end{array}$ & $\begin{array}{c}-.742 * * \\
(.378)\end{array}$ & $\begin{array}{l}-.076 \\
(.215)\end{array}$ & $\begin{array}{l}-.844 * \\
(.451)\end{array}$ & $\begin{array}{c}.039 \\
(.238)\end{array}$ \\
\hline ASIAN & $\begin{array}{c}2.064 * * \\
(.903)\end{array}$ & $\begin{array}{c}.571 \\
(1.312)\end{array}$ & $\begin{array}{c}2.756^{* *} \\
(1.256)\end{array}$ & $\begin{array}{c}1.199 \\
(2.006)\end{array}$ & $\begin{array}{c}1.89 \\
(1.833)\end{array}$ \\
\hline BREAK & $\begin{array}{c}.34 \\
(.283)\end{array}$ & $\begin{array}{l}.159 \\
(.408)\end{array}$ & $\begin{array}{c}.491 \\
(.394)\end{array}$ & $\begin{array}{c}.054 \\
(.562) \\
\end{array}$ & $\begin{array}{c}.76 \\
(.521) \\
\end{array}$ \\
\hline LUNCH & $\begin{array}{l}.359 * * \\
(.117)\end{array}$ & $\begin{array}{l}.442 * * \\
(.163)\end{array}$ & $\begin{array}{l}.258 \\
(.171) \\
\end{array}$ & $\begin{array}{l}.397 * \\
(.214) \\
\end{array}$ & $\begin{array}{l}.132 \\
(.206) \\
\end{array}$ \\
\hline ASGUEST & $\begin{array}{c}-1.109 * * \\
(.135)\end{array}$ & $\begin{array}{c}-1.186 * * \\
(.191)\end{array}$ & $\begin{array}{c}-.968 * * \\
(.193)\end{array}$ & $\begin{array}{c}-1.319 * * \\
(.231)\end{array}$ & $\begin{array}{c}-1.006 * * \\
(0.222)\end{array}$ \\
\hline BYGUEST & $\begin{array}{l}.978 * * \\
(.104)\end{array}$ & $\begin{array}{c}1.039 * * \\
(.136)\end{array}$ & $\begin{array}{l}.986 * * \\
(.165)\end{array}$ & $\begin{array}{c}1.131 * * \\
(.184)\end{array}$ & $\begin{array}{l}.969 * * \\
(0.187)\end{array}$ \\
\hline FEM & $\begin{array}{l}-.155 \\
(.85)\end{array}$ & $\begin{array}{c}.726 \\
(1.177)\end{array}$ & $\begin{array}{l}-1.069 \\
(1.242)\end{array}$ & $\begin{array}{c}-2.484 \\
(2.861)\end{array}$ & $\begin{array}{l}-4.061 \\
(2.862)\end{array}$ \\
\hline HH0_1 & $\begin{array}{l}-3.901 \\
(2.876)\end{array}$ & $\begin{array}{l}-2.182 \\
(4.086)\end{array}$ & $\begin{array}{l}-5.196 \\
(4.083)\end{array}$ & $\begin{array}{l}-8.382 \\
(5.772)\end{array}$ & $\begin{array}{l}-2.316 \\
(5.537)\end{array}$ \\
\hline HH2_17 & $\begin{array}{c}1.593 \\
(2.198) \\
\end{array}$ & $\begin{array}{c}-.291 \\
(3.162)\end{array}$ & $\begin{array}{l}3.017 \\
(3.07) \\
\end{array}$ & $\begin{array}{c}-8.64 \\
(5.063)\end{array}$ & $\begin{array}{c}4.704 \\
(4.651)\end{array}$ \\
\hline HH61p & $\begin{array}{c}3.249 \\
(3.562)\end{array}$ & $\begin{array}{c}-3.78 \\
(5.404)\end{array}$ & $\begin{array}{c}7.713 \\
(4.785)\end{array}$ & $\begin{array}{l}-8.137 \\
(8.246)\end{array}$ & $\begin{array}{l}-4.943 \\
(8.913)\end{array}$ \\
\hline STAMP & $\begin{array}{l}2.001 * * \\
(.577)\end{array}$ & & & & \\
\hline LFE & & & & & $\begin{array}{c}-12.584 * * \\
(2.245)\end{array}$ \\
\hline constant & $\begin{array}{c}18.597 * * \\
(1.727)\end{array}$ & $\begin{array}{c}19.179 * * \\
(2.491)\end{array}$ & $\begin{array}{c}20.238 * * \\
(2.341)\end{array}$ & $\begin{array}{c}32.738 * * \\
(4.773)\end{array}$ & $\begin{array}{c}26.309 * * \\
(4.251)\end{array}$ \\
\hline Adjusted $\mathrm{R}^{2}$ & .2571 & .2937 & .2172 & .2812 & .3085 \\
\hline MPC(fsb) & $\begin{array}{l}.318 * * \\
(.089)\end{array}$ & $\begin{array}{l}.416 * * \\
(.132)\end{array}$ & $\begin{array}{l}.221 * \\
(.122)\end{array}$ & $\begin{array}{c}.034 \\
(.181)\end{array}$ & $\begin{array}{l}0.406 * \\
(.167)\end{array}$ \\
\hline MPC(inc) & $\begin{array}{l}.046^{* *} \\
(.01)\end{array}$ & $\begin{array}{l}.051 * * \\
(.014)\end{array}$ & $\begin{array}{l}.037^{* *} \\
(.014)\end{array}$ & $\begin{array}{c}.018 \\
(.021)\end{array}$ & $\begin{array}{l}.016 \\
(.02)\end{array}$ \\
\hline $\begin{array}{l}\text { MPC(fsb) - } \\
\text { MPC(inc) }\end{array}$ & $\begin{array}{l}.272 * * \\
(.089)\end{array}$ & $\begin{array}{l}.365 * * \\
(.132)\end{array}$ & $\begin{array}{l}.184 \\
(.122) \\
\end{array}$ & $\begin{array}{l}.017 \\
(.18) \\
\end{array}$ & $\begin{array}{c}.39^{*} \\
(.167) \\
\end{array}$ \\
\hline
\end{tabular}

$*$ significant at $90 \%$ level

**significant at $95 \%$ level 
Table A.3

Regression Results for Double-Log Model (b)

\begin{tabular}{|c|c|c|c|c|c|}
\hline & & & & Single-Adult he & households \\
\hline & $\begin{array}{l}\text { Pooled } \\
\text { Sample } \\
(n=953)\end{array}$ & $\begin{array}{c}\text { Unconstrained } \\
\text { Stamp } \\
(n=487)\end{array}$ & $\begin{array}{c}\text { Check } \\
(n=466)\end{array}$ & $\begin{array}{c}\text { Unconstrained } \\
\text { Stamp } \\
(\mathbf{n}=\mathbf{2 8 1})\end{array}$ & $\begin{array}{c}\text { Check } \\
(n=283)\end{array}$ \\
\hline LNTOTINC & $\begin{array}{l}.338 * * \\
(.045)\end{array}$ & $\begin{array}{l}.385 * * \\
(0.091)\end{array}$ & $\begin{array}{l}.295 * * \\
(.069)\end{array}$ & $\begin{array}{c}.06 \\
(.091)\end{array}$ & $\begin{array}{l}.207 * * \\
(.101)\end{array}$ \\
\hline $\begin{array}{l}\text { LNTOTINC } \\
* \text { LFE }\end{array}$ & & & & & $\begin{array}{l}.615 \\
(.438)\end{array}$ \\
\hline PROP & $\begin{array}{l}.836 * * \\
(.186)\end{array}$ & $\begin{array}{l}1.065 \\
(.247)\end{array}$ & $\begin{array}{l}.608 * * \\
(.277)\end{array}$ & $\begin{array}{c}.231 \\
(.356)\end{array}$ & $\begin{array}{l}.821 * * \\
(.344)\end{array}$ \\
\hline $\begin{array}{l}\text { PROP } \\
* \text { LFE }\end{array}$ & & & & & $\begin{array}{l}4.835^{* * *} \\
(2.117)\end{array}$ \\
\hline LNHHSIZE & $\begin{array}{c}-.375 * * \\
(.057) \\
\end{array}$ & $\begin{array}{c}-.327 * * \\
(.076)\end{array}$ & $\begin{array}{l}-.42 * * \\
(.084)\end{array}$ & $\begin{array}{c}-.244 * * \\
(.122)\end{array}$ & $\begin{array}{c}-.306 * * \\
(.135) \\
\end{array}$ \\
\hline GIFT & $\begin{array}{l}-.012 * \\
(.007)\end{array}$ & $\begin{array}{l}.03 * * \\
(.002)\end{array}$ & $\begin{array}{c}-.036^{* * *} \\
(.009)\end{array}$ & $\begin{array}{l}.022^{*} \\
(.012)\end{array}$ & $\begin{array}{c}-.036^{* *} \\
(.01)\end{array}$ \\
\hline WIC & $\begin{array}{c}-.028 * * \\
(.009)\end{array}$ & $\begin{array}{l}-.024 \\
(.017) \\
\end{array}$ & $\begin{array}{c}-.028 * * \\
(.012)\end{array}$ & $\begin{array}{l}-.025 \\
(.019) \\
\end{array}$ & $\begin{array}{l}-.019 \\
(.011)\end{array}$ \\
\hline ASIAN & $\begin{array}{l}.109 * * \\
(.045)\end{array}$ & $\begin{array}{c}.039 \\
(.059) \\
\end{array}$ & $\begin{array}{l}.144 * * \\
(.068)\end{array}$ & $\begin{array}{c}.069 \\
(.085) \\
\end{array}$ & $\begin{array}{l}.072 \\
(.09) \\
\end{array}$ \\
\hline BREAK & $\begin{array}{c}.007 \\
(.014) \\
\end{array}$ & $\begin{array}{c}.002 \\
(.018) \\
\end{array}$ & $\begin{array}{c}.009 \\
(.021) \\
\end{array}$ & $\begin{array}{l}-.007 \\
(.024) \\
\end{array}$ & $\begin{array}{c}.028 \\
(.025) \\
\end{array}$ \\
\hline LUNCH & $\begin{array}{l}.021 * * \\
(.006)\end{array}$ & $\begin{array}{l}.021 * * \\
(.007)\end{array}$ & $\begin{array}{l}.019 * * \\
(.009)\end{array}$ & $\begin{array}{l}.02 * * \\
(.009)\end{array}$ & $\begin{array}{l}.009 \\
(.01)\end{array}$ \\
\hline ASGUEST & $\begin{array}{c}-.053 * * \\
(.007)\end{array}$ & $\begin{array}{c}-.053^{* *} \\
(.009)\end{array}$ & $\begin{array}{c}-.048 * * \\
(.01)\end{array}$ & $\begin{array}{c}-.058 * * \\
(.01)\end{array}$ & $\begin{array}{c}-.048 * * \\
(.011)\end{array}$ \\
\hline BYGUEST & $\begin{array}{l}.037 * * \\
(.005)\end{array}$ & $\begin{array}{l}.036 * * \\
(.006)\end{array}$ & $\begin{array}{l}.044 * * \\
(.009)\end{array}$ & $\begin{array}{l}.039 * * \\
(.008)\end{array}$ & $\begin{array}{l}.045^{* *} \\
(.009) \\
\end{array}$ \\
\hline FEM & $\begin{array}{l}-.091 * * \\
(0.045)\end{array}$ & $\begin{array}{c}-.03 \\
(.057) \\
\end{array}$ & $\begin{array}{c}-.165 * * \\
(.069)\end{array}$ & $\begin{array}{l}-.131 \\
(.12)\end{array}$ & $\begin{array}{l}-.267 * \\
(.139) \\
\end{array}$ \\
\hline HHO_1 & $\begin{array}{c}.184 \\
(.151) \\
\end{array}$ & $\begin{array}{c}.233 \\
(.193) \\
\end{array}$ & $\begin{array}{c}.117 \\
(.234) \\
\end{array}$ & $\begin{array}{l}-.194 \\
(.278) \\
\end{array}$ & $\begin{array}{l}-.023 \\
(.308) \\
\end{array}$ \\
\hline HH2_17 & $\begin{array}{l}.451 * * \\
(.122)\end{array}$ & $\begin{array}{l}.376 * * \\
(.158) \\
\end{array}$ & $\begin{array}{l}.499 * * \\
(.183)\end{array}$ & $\begin{array}{l}-.128 \\
(.261)\end{array}$ & $\begin{array}{c}.335 \\
(.276) \\
\end{array}$ \\
\hline HH61p & $\begin{array}{c}.279 \\
(.178)\end{array}$ & $\begin{array}{l}-.068 \\
(.242) \\
\end{array}$ & $\begin{array}{l}.445^{*} \\
(.259)\end{array}$ & $\begin{array}{l}-.162 \\
(.34)\end{array}$ & $\begin{array}{l}-.206 \\
(.434) \\
\end{array}$ \\
\hline STAMP & $\begin{array}{l}.11 * * \\
(.029)\end{array}$ & & & & \\
\hline LFE & & & & & $\begin{array}{c}-4.273 * * \\
(2.073)\end{array}$ \\
\hline constant & $\begin{array}{c}1.634 * * \\
(.24)\end{array}$ & $\begin{array}{c}1.442 * * \\
(.317)\end{array}$ & $\begin{array}{c}1.925 * * \\
(.359)\end{array}$ & $\begin{array}{l}3.25 * * \\
(.493)\end{array}$ & $\begin{array}{c}2.431 * * \\
(.516)\end{array}$ \\
\hline Adjusted $\mathrm{R}^{2}$ & .2854 & .3462 & .2523 & .2724 & .4060 \\
\hline
\end{tabular}

*significant at $90 \%$ level

**significant at $95 \%$ level 
Table A.3 (continued)

Regression Results for Double-Log Model (b)

\begin{tabular}{|c|c|c|c|c|c|}
\hline & & & & Single-Adult h & households \\
\hline & $\begin{array}{c}\text { Pooled } \\
\text { Sample } \\
(\mathrm{n}=953)\end{array}$ & $\begin{array}{c}\text { Unconstrained } \\
\text { Stamp } \\
(n=487)\end{array}$ & $\begin{array}{c}\text { Check } \\
(n=466)\end{array}$ & $\begin{array}{c}\text { Unconstrained } \\
\text { Stamp } \\
(\mathbf{n}=\mathbf{2 8 1})\end{array}$ & $\begin{array}{c}\text { Check } \\
(n=283)\end{array}$ \\
\hline MPC(fsb) & $\begin{array}{l}.307 * * \\
(.057)\end{array}$ & $\begin{array}{l}.393 * * \\
(.078) \\
\end{array}$ & $\begin{array}{l}.235 * * \\
(.084)\end{array}$ & $\begin{array}{l}.078 * * \\
(.114) \\
\end{array}$ & $\begin{array}{l}.269 * * \\
(.111)\end{array}$ \\
\hline MPC(inc) & $\begin{array}{c}.069 * * \\
(.01)\end{array}$ & $\begin{array}{l}.075^{* *} * \\
(.013)\end{array}$ & $\begin{array}{l}.063 * * \\
(.014)\end{array}$ & $\begin{array}{l}.009 \\
(.02)\end{array}$ & $\begin{array}{c}.032 \\
(.022)\end{array}$ \\
\hline $\begin{array}{l}\text { MPC(fsb) - } \\
\text { MPC(inc) }\end{array}$ & $\begin{array}{l}.238 * * \\
(.053)\end{array}$ & $\begin{array}{l}.318 * * \\
(.074)\end{array}$ & $\begin{array}{l}.172 * * \\
(.078)\end{array}$ & $\begin{array}{c}.069 \\
(.107)\end{array}$ & $\begin{array}{l}.237 * * \\
(.099)\end{array}$ \\
\hline
\end{tabular}

MPCs calculated at median values (numbers in parentheses are standard errors)

*significant at $90 \%$ level

**significant at $95 \%$ level

\section{Notes on Tables A.2 and A.3}

We report pooled and separate regressions results for the full sample, since we fail to reject the hypothesis that the marginal propensities to consume are different for the two groups. (For the linear model, the F-statistic for the joint hypothesis test that the coefficients of cash income, stamp benefits, and household size interacted with the stamp dummy are zero is 1.15. For the double-log model, it is .60. In both cases these are distributed as $\mathrm{F}(3,934)$ and we fail to reject the hypothesis that these coefficients interacted with the stamp dummy are zero.) For the single-adult headed households, we report only the separate sub-sample regressions since we reject the hypothesis of poolability. (In this case the F-statistics are 2.81 and 3.32 respectively, both of which are distributed as $\mathrm{F}(3,545)$. At the $95 \%$ confidence level, we reject that these subsamples can be pooled.)

Gift income seems to affect the check and stamp households quite differently. For the stamp households the sign is opposite of what we would expect. When the sample is pooled, this variable is insignificant. Dropping this variable had no effect on MPC(fsb) or MPC(inc). Lunch subsidies were, surprisingly, positively related to food expenditure. This was consistent for every sub-sample of data. It could reflect an effect on preference development or taste for certain kinds of food which may increase family food expenditure. The age proportion data was only significant for the double-log model. The higher the proportion in the 2-17 year age range, the higher the expenditure on food. This may reflect a focus on nutrition for children or the effects of advertising and peer pressure. We tested several different ways of breaking up the age ranges and this did not affect the main results. 
Table A.4

San Diego Experiment: Unconstrained Single-adult headed Households

\begin{tabular}{|c|c|c|}
\hline & Stamp & Check \\
\hline Number & 281 & 283 \\
\hline Monthly cash income per person & $\$ 271$ & $\$ 281$ \\
\hline Monthly food stamp benefit per person & $\$ 36$ & $\$ 37$ \\
\hline Benefits as proportion of income & $13.4 \%$ & $13.7 \%$ \\
\hline HH with WIC vouchers & $9.5 \%$ & $10.3 \%$ \\
\hline Average amount & $\$ 68$ & $\$ 50$ \\
\hline HH with school breakfast subsidy & $15.8 \%$ & $19.8 \%$ \\
\hline Average amount & $\$ 30$ & $\$ 26$ \\
\hline HH with school lunch subsidy & $47.7 \%$ & $52.7 \%$ \\
\hline Average amount & $\$ 53$ & $\$ 51$ \\
\hline HH reporting positive gifts of food & $34.0 \%$ & $39.7 \%$ \\
\hline Average amount & $\$ 6$ & $\$ 5$ \\
\hline Monthly food expenditure per person & $\$ 98$ & $\$ 94$ \\
\hline $\begin{array}{l}\text { Weekly average number of meals } \\
\text { eaten as guest per household member }\end{array}$ & 2.45 & 2.36 \\
\hline $\begin{array}{l}\text { Weekly average number of meals } \\
\text { eaten by guest per household member }\end{array}$ & 3.22 & 3.15 \\
\hline \multicolumn{3}{|l|}{ Information on Household Head } \\
\hline$\%$ employed & $13.0 \%$ & $12.2 \%$ \\
\hline$\%$ Asian/Pacific & $7.7 \%$ & $9.5 \%$ \\
\hline$\%$ Hispanic & $30.2 \%$ & $30.5 \%$ \\
\hline$\%$ Black & $27.0 \%$ & $22.5 \%$ \\
\hline$\%$ White & $32.3 \%$ & $36.3 \%$ \\
\hline Married & $7.4 \%$ & $6.9 \%$ \\
\hline Widowed & $3.5 \%$ & $4.2 \%$ \\
\hline Divorced & $25.3 \%$ & $25.6 \%$ \\
\hline Legally separated & $20.7 \%$ & $18.7 \%$ \\
\hline Completed high school & $63.2 \%$ & $56.1 \%$ \\
\hline \multicolumn{3}{|l|}{ Household Information } \\
\hline Average size & 3.1 & 2.9 \\
\hline \multicolumn{3}{|l|}{ Percentage of households with: } \\
\hline one member & $3.9 \%$ & $5.3 \%$ \\
\hline two members & $34.4 \%$ & $35.5 \%$ \\
\hline three members & $30.5 \%$ & $34.4 \%$ \\
\hline four members & $19.3 \%$ & $15.6 \%$ \\
\hline \multicolumn{3}{|l|}{ Percentage of households with: } \\
\hline child from age $0-11$ & $84.9 \%$ & $85.1 \%$ \\
\hline child from age $12-17$ & $30.5 \%$ & $27.9 \%$ \\
\hline member over 51 & $5.3 \%$ & $3.4 \%$ \\
\hline Avg no. of children for hh with children & 2.1 & 2.0 \\
\hline
\end{tabular}


Back to text

Figure 1

All Households

Nonparametric Regression: Linear Specification

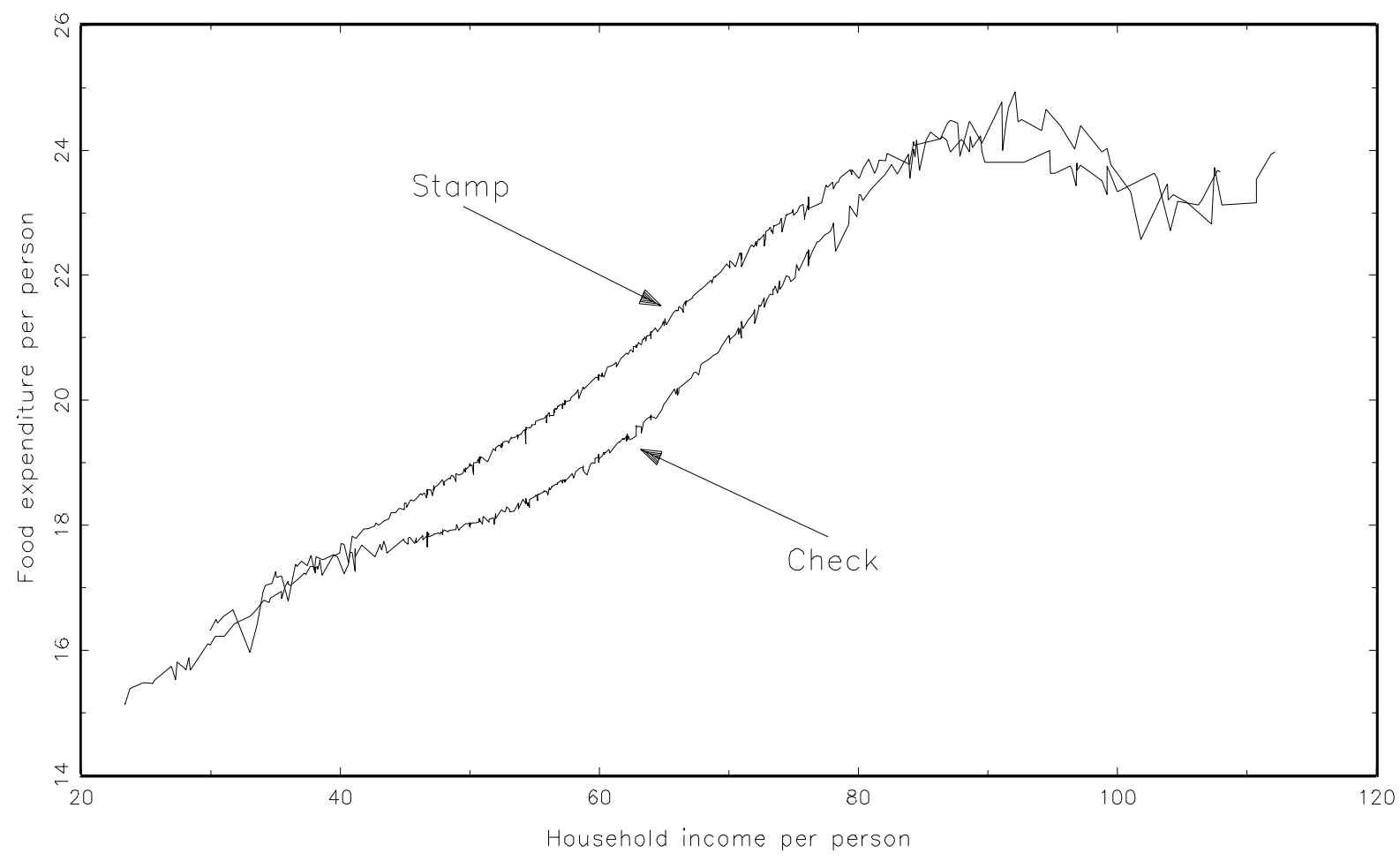

Nonparametric Regression: Double-Log Specification

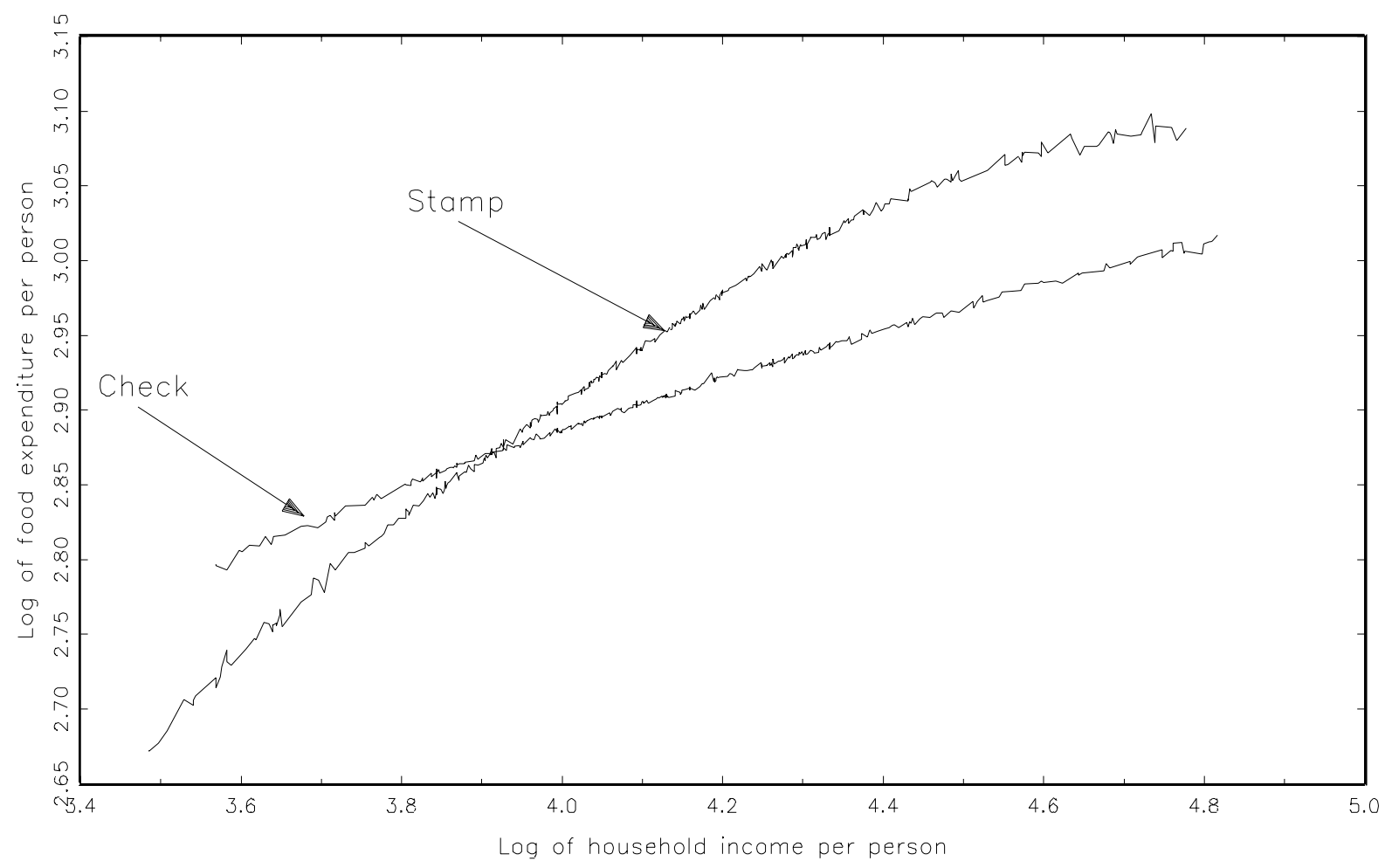


Back to text

Figure 2

Single-adult Headed Households

Nonparametric Regression: Linear Specification

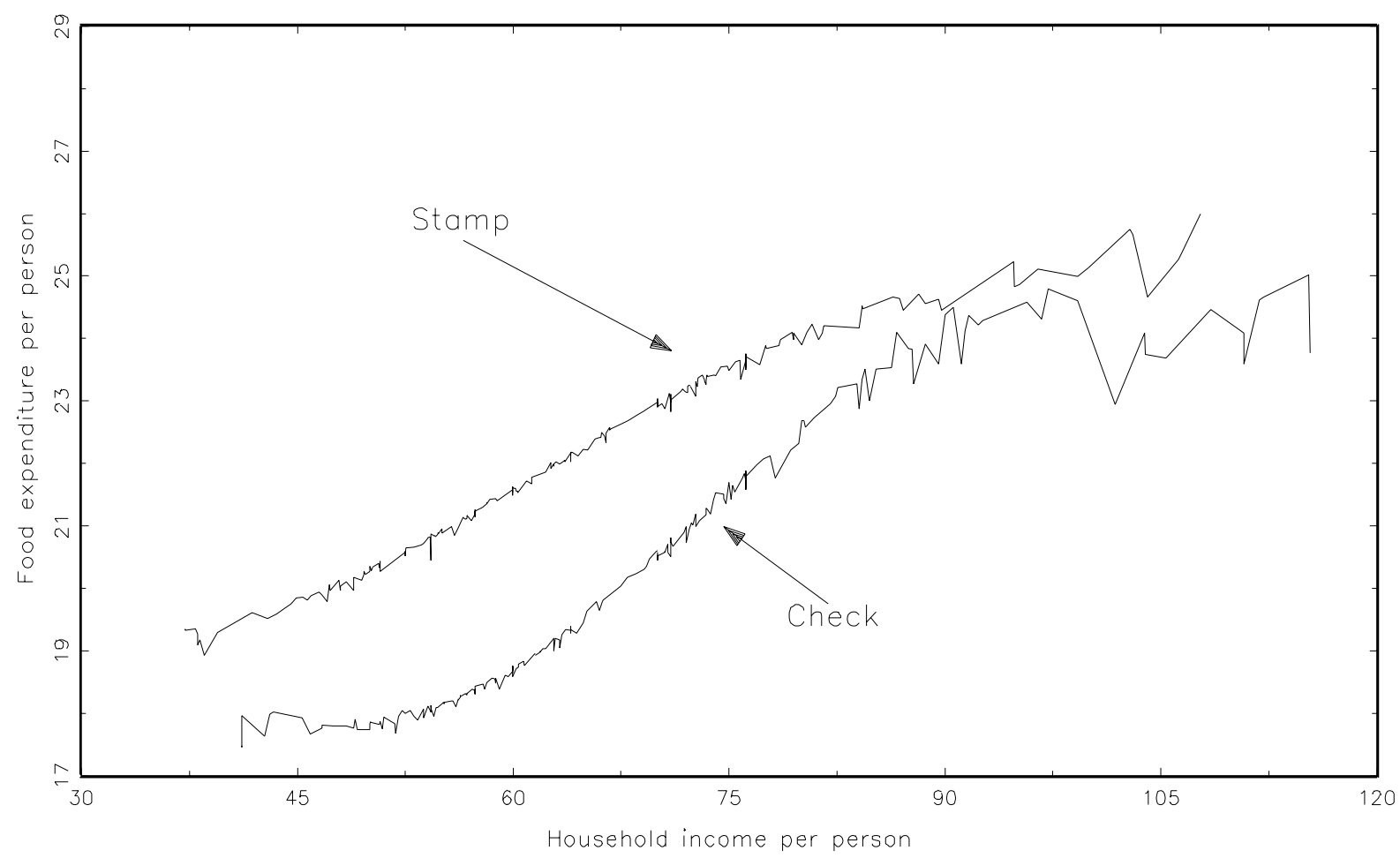

Nonparametric Regression: Double-Log Specification

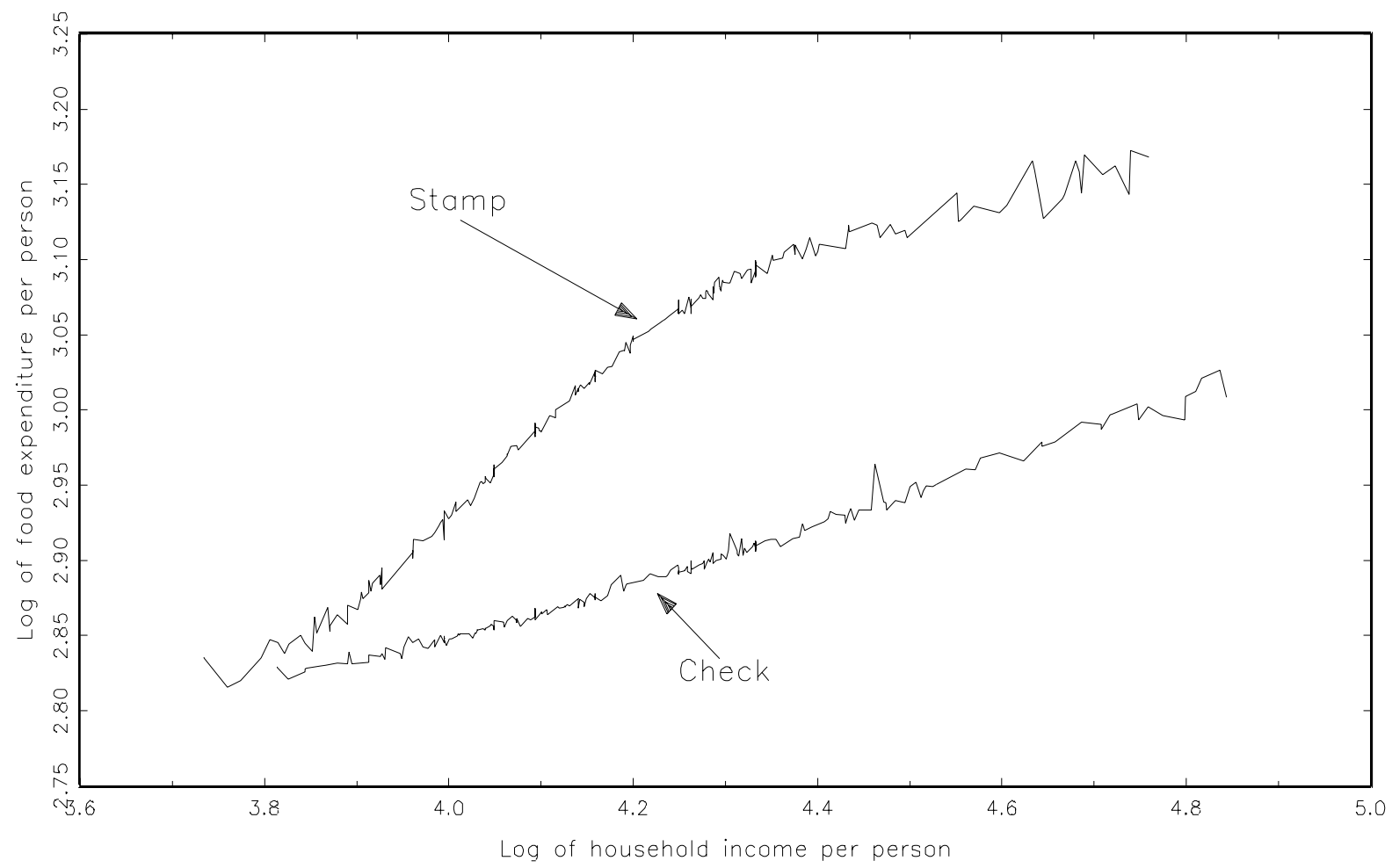

